\title{
A INTEGRAÇÃO ENTRE A VIGILANCIA E A ASSISTÊNCIA NO ACOMPANHAMENTO AOS CASOS DE SÍNDROME CONGÊNITA DO ZIKA VíRUS
}

\author{
Isabeli Karine Martins Castelaneli \\ Estudante da graduação de enfermagem - UNICAMP \\ isakm.cast@gmail.com
}

INTRODUÇÃO: Atualmente foi comprovado a associação entre a infecção por Zika Virus (ZIKV) e os sintomas neurológicos e osteoarticulares, detectados em neonatos e crianças infectadas na gestação, originando o termo Síndrome Congênita do ZIKV. Com base na complexidade do atendimento desta síndrome, percebe-se a necessidade de integração entre as equipes de vigilância epidemiológica e a assistência, no sentido de garantir a qualidade das informações e do melhor cuidado a esses pacientes, buscando também cumprir os novos protocolos de acompanhamentos. OBJETIVO: Analisar a integração entre a Vigilância em Saúde e Assistência no acompanhamento aos casos de ZIKV em gestantes e casos de Síndrome Congênita de ZIKV na Rede de Atenção à Saúde do município de Campinas. MÉTODO: Trata-se de estudo de caso com participação de profissionais de um Centro de Saúde e uma equipe de Vigilância em Saúde regional. Utilizou-se de abordagem quantitativa e qualitativa para descrever as etapas do processo de trabalho da vigilância e de assistência nos casos confirmados de zika em gestantes e seus bebês. $O$ critério de escolha do campo se deu em função da maior concentração de casos de ZIKV por região da cidade e por Centro de Saúde, utilizando-se do banco de dados da doença disponibilizado pelo nível central da Vigilância em Saúde Municipal. Os dados qualitativos foram analisados pela técnica de Análise de Conteúdo, a partir de categorias temáticas identificadas no estudo. A pesquisa foi aprovada pelo Comitê de Ética em Pesquisa da Universidade sob parecer n².583.943. RESULTADOS: condução dos casos: ocorre por um fluxo operacional elaborado e implantado; integração entre a vigilância e assistência: acontece por meio da supervisão dos casos e ações conjuntas no território; formação dos profissionais: a síndrome do ZIKV foi abordada por meio de seminários temáticos e treinamentos principalmente no ano de 2016, porém em 2017 houve declínio da sensibilização das equipes; dificuldades: fornecer atendimento integral a longo prazo devido a falta de recursos 
humanos, financeiros e atendimento especializado, incluindo aí as referências e contra-referência para os casos; Facilidades: implantação do fluxo de atendimento do ZIKV, semelhantes ao já consolidado no atendimento de outras arboviroses, além de políticas como a puericultura. CONSIDERAÇÕES FINAIS: Conclui-se que houve integração entre a vigilância e assistência, mas ocorrem limitações provocadas, principalmente, devido às dificuldades estruturais encontradas na Rede de Atenção à Saúde.

Palavras-chave: Infecção pelo ZIKV. Atenção Primária à Saúde. Vigilância em Saúde Pública. 